\title{
Grasshopper optimization algorithm optimized multistage controller for automatic generation control of a power system with FACTS devices
}

\author{
Pratap Chandra Nayak, Ramesh Chandra Prusty *i) and Sidhartha Panda
}

\begin{abstract}
This paper uses a Grasshopper Optimization Algorithm (GOA) optimized PDF plus (1 + PI) controller for Automatic generation control (AGC) of a power system with Flexible AC Transmission system (FACTS) devices. Three differently rated reheat turbine operated thermal units with appropriate generation rate constraint (GRC) are considered along with different FACTS devices. A new multistage controller design structure of a PDF plus $(1+\mathrm{PI})$ is introduced in the FACTS empowered power system for AGC while the controller gains are tuned by the GOA. The superiority of the proposed algorithm over the Genetic Algorithm (GA) and Particle Swarm Optimization (PSO) algorithms is demonstrated. The dynamic responses of GOA optimized PDF plus (1 + PI) are compared with PIDF, PID and PI controllers on the same system. It is demonstrated that GOA optimized PDF plus (1 + PI) controller provides optimum responses in terms of settling time and peak deviations compared to other controllers. In addition, a GOA-tuned PDF plus (1 + PI) controller with Interline Power Flow Controller (IPFC) exhibits optimal results compared to other FACTS devices. The sturdiness of the projected controller is validated using sensitivity analysis with numerous load patterns and a wide variation of parameterization. To further validate the real-time feasibility of the proposed method, experiments using OPAL-RT OP5700 RCP/HIL and FPGA based real-time simulations are carried out.
\end{abstract}

Keywords: Automatic generation control, FACTS devices, Multistage controller, Grasshopper optimization algorithm

\section{Introduction}

In a multi-area power system, qualitative, reliable, secure, stable and economic action of the system requires stable frequency and power transmission across a tieline preserved at their nominal values. Symmetry in a power system will be maintained when proper coordination is established between power requirement and generation. Two control mechanisms are assigned, i.e., reactive power control (Automatic voltage regulator AVR) which maintains voltage profile and real power control through the AGC system [1] for frequency stabilization. The responsibility of AGC in a multi-area

*Correspondence: ramesh.prusty82@gmail.com

Department of Electrical Engineering, VSSUT, Burla, Odisha 768018, India power network is to limit the transient frequency deviation, inter-line power exchange, and to reduce steady-state errors to zero [2]. An epidemic power system is an amalgamation of a large electrical network and within the network, each area is known as a control area and the areas are braided with one another over various tie-lines. In an electric network, the system operation must be proficient in establishing equilibrium in exchange power across a tie-line and in securing frequency stabilization. Many nonlinear loads (equipped with power semiconductor devices) interlinked with a dispersed power system network introduce large transient disturbances in the electrical network resulting in a mismatch between generation and demand. Thus, the 
automatic control system has to be upgraded with modern techniques for stable, reliable and economical operation [3].

In a modern power system, the rapid development of power semiconductor devices gives opportunities to design fast-acting FACTS devices [4]. Power system stability has reached a new height and power flow control becomes more flexible using modern FACTS devices. Much recent research explores the effect of FACTS devices in AGC, e.g., Thyristor controlled phase shifter (TCPS), Static Synchronous Series Compensator (SSSC) and various combinations equipped in series with a tie-line integrated with SMES have been implemented to normalize frequency deviations under various restraints of a 2 -area system [5]. Steadiness of frequency oscillation is achieved by a fractional order based SSSC controller in [6] while TCPS-SMES was implemented in DFIG-based wind farm integrated power systems in [7] [8, 9]. used redox flow batteries interlinked with IPFC and a Thyristor Controlled Series Capacitor (TCSC), while [10, 11] used TCSC for stability control in IPFC, and an SMES-UPFC combination was used in a 2 -area 6 -unit system in [12].

Many have introduced various modern control strategies including modified structures of the classical controllers of I, PI and PID in the AGC system. The dynamic responses of classical controllers in AGC have been evaluated in [13, 14], while [15] proposed parallel 2DOF-PID for LFC in a power system with GDB. The fuzzy-PID controller was preferred to establish cohesion in power system dynamic behavior in [16-18], while cascaded PD-PID and PI-PD controllers were used in [19, 20] because of their adequate results, simplicity, reliability and performance. A 2DOF controller was implemented in [19] to minimize the steady-state error and to establish stability in the system, while [21,22] satisfied a system necessity by introducing a metamorphic modern $\mathrm{PDF}+(1+\mathrm{PI})$ controller which helped in developing the responses of transient and steady-state error to diminish with different dynamic responses with various parts.

In this paper, a PDF+ $(1+\mathrm{PI})$ controller consisting of a PD controller with filter and a $(1+\mathrm{PI})$ controller connected in series, is examined with the influence of FACT $S$ devices in an AGC multi-area thermal power system. Contemporary memetic nature-inspired innovations have been evolved to carry out a comprehensive search. The efficacy of the memetic algorithm can be assessed by evidence that they emulate the finest outcome globally, specifically the excerpt of the competent in organic systems that have emerged by instinctive assortment over decades. From the literature survey, it is evident that many optimization techniques/ controllers have been applied to various problems but no meta-heuristic method is exactly appropriate for all types of problems and there is scope for improvement by proposing new techniques/controller.

Conventional tuning methods are based on a single objective trial and error type. This often takes up more time and most often produces substandard results. Reference [13] used hybrid DEPS, while [15] adopted DE and [18] used PSO for optimization. However, these classical methods have the problem of getting trapped in local optima. Many methods have been used to try to address these problems, e.g., firefly algorithm (FA) [12], Symbiotic Organisms Search SOS [16], BAT [19], Grey Wolf Optimization GWO [20], and Cuckoo Search (CS) [23]. The efficacy of the sine cosine algorithm in the AGC system with FACTS devices was explored in [24], while better dynamic performance using GWO was obtained in [21] and in [22], the primacy of GOA with a 2stage controller was explored.

The GOA approach uses a node finite input for excitation and it has a simple user interface. It was extensively used in [25] for tuning controller gains. In this paper, the GOA algorithm is embedded with a PDF plus $(1+$ PI) controller in the AGC of a 3-area thermal power network for the escalation of gains in the presence of contrasting FACTS devices.

Sensitivity investigation observed the robustness of the most favorable controller gains [21-23]. Similar investigation has been carried out for the optimum controller in the presence of FACTS devices in AGC, and the most convenient objective function for optimum controller and FACTS devices is investigated.

The main objectives of the present research work are:

- Introduction of GOA for extensive modulation of controller gains of an AGC in a 3-area thermal power network.

- Introduction of a metamorphic PDF plus (1 + PI) controller in the AGC, consisting of a filter with PD and $(1+\mathrm{PI})$. The time-variant responses are equated with PI, PID and PIDF controllers for efficacy measurement.

- Comparison of the dynamic performance of a 3-area thermal power network with FACTS devices along with a metamorphic PDF plus (1+PI) controller.

- To compare the performance of GOA with PSO and GA for a controller design problem for the same test system.

- Performance comparison of IPFC with SSSC, TCPS and TCSC for frequency regulation.

- Sensitivity analysis of a 3-area thermal power network with the best location of IPFC and optimum controller gains, by changing the percentage of step load perturbation (SLP) and system parameters. 
- Validation of simulation results by an OPAL-RT OP5700 real-time simulator.

\section{Model investigated}

A 3-area thermal power network is proposed for analysis, where the size of area1 is $2000 \mathrm{MW}$, area2 is 6000 MW and area3 is $1200 \mathrm{MW}$. In this network model, nonlinearity constraints are extensively introduced by the implementation of GRC which is set at $3 \%$ with a reheat turbine in each control section. The nominal parameters of the model are given in Table 7 in Appendix. Several classic PI, PID and PDF controllers with the metamorphic PDF plus $(1+\mathrm{PI})$ controller are considered individually for study. Dynamic investigations of the 3area thermal power network with the independent influence of SSSC, TCSC, TCPS and IPFC are carried out in the presence of the GOA technique-tuned PDF plus $(1+\mathrm{PI})$ controller. The dynamic performance in each control area is estimated by setting SLP at $1 \%$. The proposed control model of the 3-area thermal network is presented in Fig. 1 and the relevant parameters are shown. The different possible combinations of various controllers with several FACT devices are optimized with GA, PSO and GOA for comparison with the proposed strategy.

\subsection{Objective function}

The objective functions, IAE, ITAE, ISE and ITSE are examined for obtaining optimum results in frequency stabilization and tie-line power control. The corresponding objective function accepts $\Delta \mathrm{F}_{\mathrm{i}}$ and $\Delta \mathrm{P}_{\text {tie }}$ i-j as inputs and actions are taken to minimize them to zero by tuned controller gains.

Mathematical expressions for the objective functions are:

$$
J_{1}=I S E=\int_{0}^{T}\left(\left(\Delta F_{i}\right)^{2}+\left(\Delta P_{t i e i-j}\right)^{2}\right) d t
$$

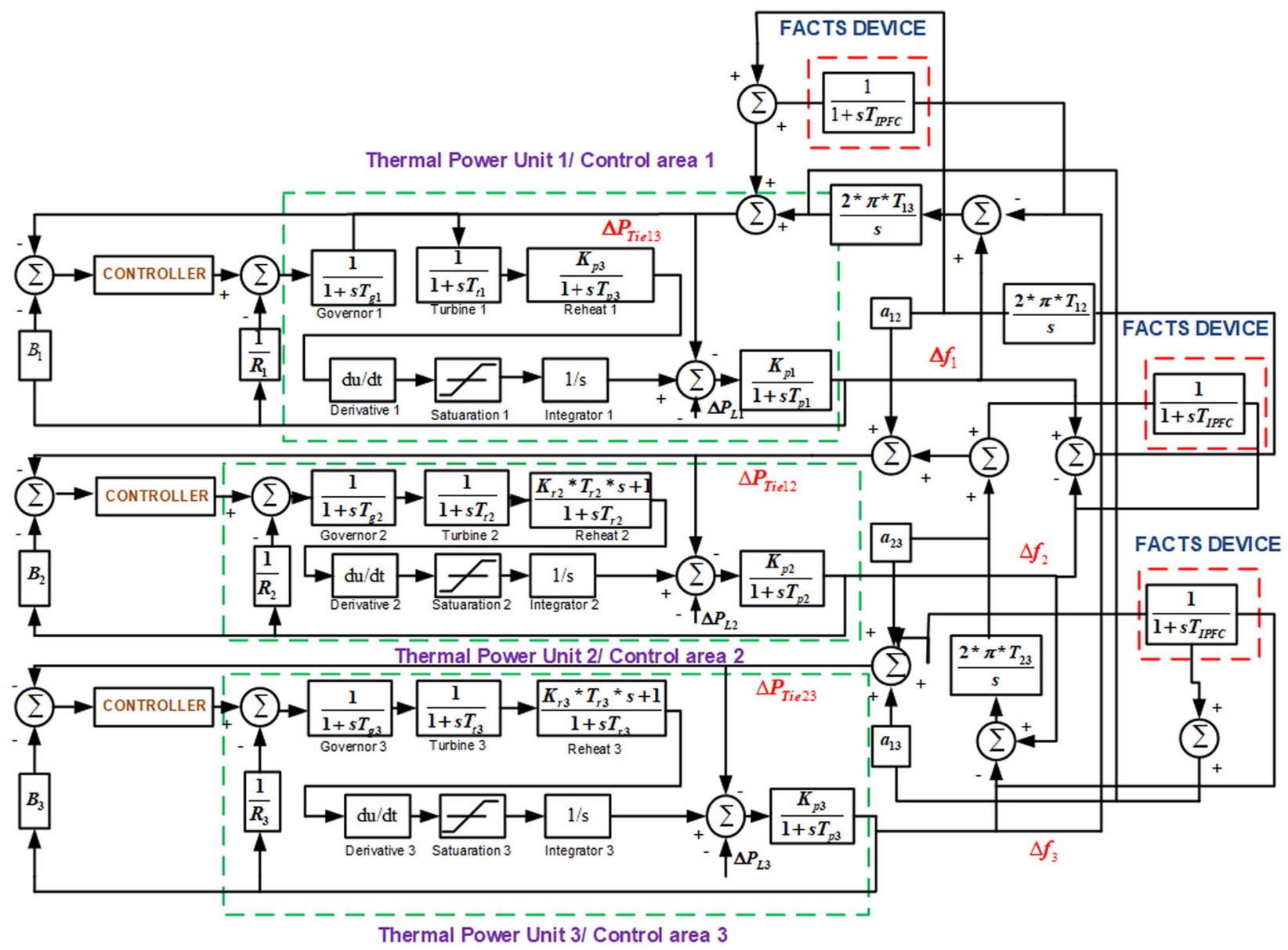

Fig. 1 Simulation prototype of a reheat turbine fitted thermal network with 1\% SLP and 3\% GRC 


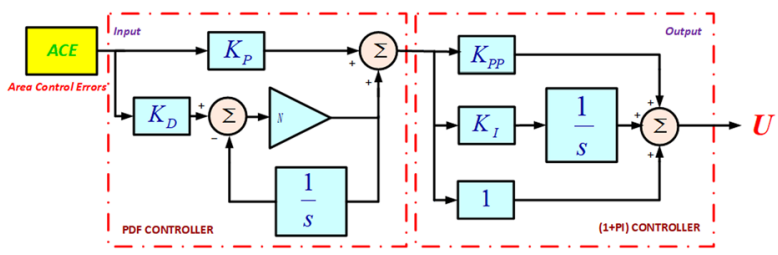

Fig. 2 Structure of PDF plus $(1+\mathrm{Pl})$ controller

$$
\begin{aligned}
& J_{2}=I T S E=\int_{0}^{T}\left(\left(\Delta F_{i}\right)^{2}+\left(\Delta P_{\text {tiei }-j}\right)^{2}\right) t d t \\
& J_{3}=I A E=\int_{0}^{T}\left(\left|\Delta F_{i}\right|+\left|\Delta P_{\text {tiei }-j}\right|\right) d t \\
& J_{4}=I T A E=\int_{0}^{T}\left(\left|\Delta F_{i}\right|+\left|\Delta P_{\text {tiei }-j}\right|\right) t d t
\end{aligned}
$$

where $\Delta F_{i}$ is the frequency fluctuation in the $i^{t h}$ area

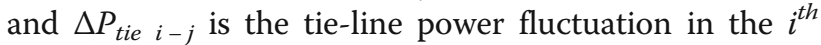
and $j^{\text {th }}$ area.

\subsection{Models of FACTS devices}

For smooth management of tie-line power control using fine adjustment of the relative phase angle between the two control areas is feasible using TCPS. This helps in the settlement of frequency oscillations as well as inter-exchange of active power across the tie-line. Transient stability can be achieved by counteracting the oscillations with well-managed controller damping on the disrupted system. SSSC incorporates a voltage with adjustable magnitude in the quadrature with the current equivalent to a controllable inductive or capacitive reactance to influence the tie-line power flow. The transfer function models of TCPS and SSSC are adapted from [5, 7]. IPFC provides reactive series compensation efficiently in inductive or capacitive fashion so that the tie-line power flow can be effectively managed by the IPFC through the injection of an accurate series reactive compensating voltage $[8,9]$. The control prototype of the IPFC has been acquired from [8]. TCSC can be employed in multi-transmission lines to effectively introduce series compensation for dynamic change in transmission line reactance. The transfer function of TCSC is presented in $[10,11]$ while the criteria of TCPS, SSSC, TCSC and IPFC are taken from $[5,7-11,21]$. As shown in Fig. 1, IPFC is in series with the three control areas.

\subsection{Proposed PDF plus $(1+\mathrm{PI})$ controller}

Having a simple system interface makes the PID controller the most encouraging tool for many studies. The PID controller offers efficacy in most transient conditions and the minimization of steady-state error in dynamic analysis of any system is demonstrated in many studies. By the presence of integral gain, rapidity in minimization of steady-state error is achieved and system stability is reduced in the transient condition. For better response in the transient condition, the integral parameter must not be engaged in action all along the transient period. With the enhancement of prominent dynamic response of the system some refitted control structures have evolved which are

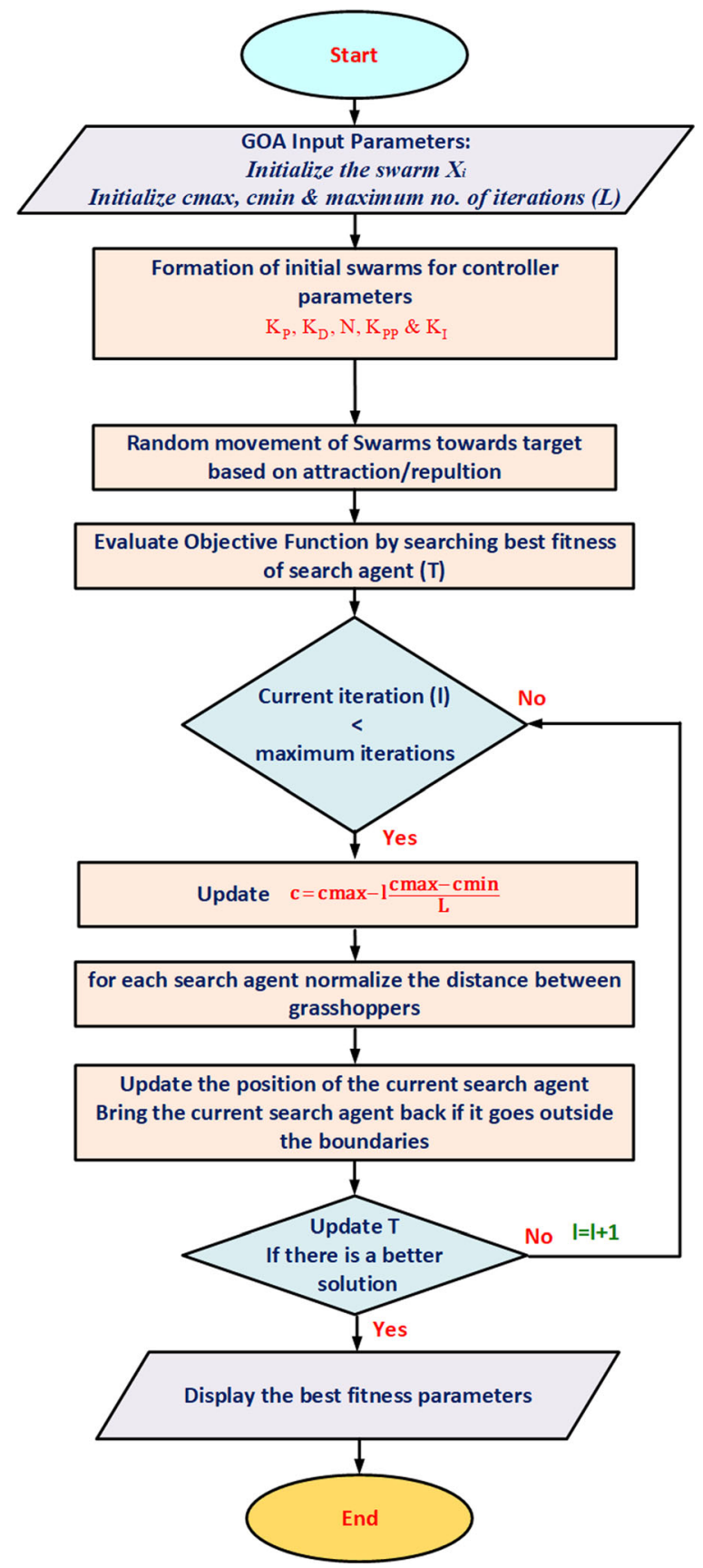

Fig. 3 The flowchart representation of GOA 
Table 1 Statistical analysis of different agents for GOA, PSO and GA optimized PDF plus (1+ PI) controllers

\begin{tabular}{|c|c|c|c|c|c|}
\hline Functions & Test Functions & Parameters & GOA & PSO & $G A$ \\
\hline \multirow[t]{4}{*}{$\overline{F 1}$} & Shifted Sphere Function & Average & $1.6219 \times 10^{56}$ & $8.931 \times 10^{66}$ & $9.2656 \times 10^{21}$ \\
\hline & \multirow{3}{*}{$f_{1}(x)=\sum_{i=1}^{n} x_{i}^{2}$} & Standard Deviation & $1.6266 \times 10^{57}$ & $7.0111 \times 10^{68}$ & $4.1437 \times 10^{22}$ \\
\hline & & Minimum & $0.1088 \times 10^{3}$ & $0.0059 \times 10^{3}$ & $0.0021 \times 10^{3}$ \\
\hline & & Maximum & $1.8291 \times 10^{68}$ & $9.468 \times 10^{66}$ & $1.8531 \times 10^{23}$ \\
\hline \multirow[t]{4}{*}{$F 2$} & Shifted Schwefel's Function & Average & $3.7673 \times 10^{67}$ & $13.045 \times 10^{11}$ & $1.4177 \times 10^{24}$ \\
\hline & \multirow{3}{*}{$f_{2}(x)=\sum_{i=1}^{n}\left|x_{i}\right|+\prod_{i=\frac{1}{2}}^{n}\left|x_{i}\right|$} & Standard Deviation & $3.7688 \times 10^{68}$ & $11.366 \times 10^{12}$ & $1.428 \times 10^{25}$ \\
\hline & & Minimum & $0.0062 \times 10^{3}$ & $0.0379 \times 10^{3}$ & $0.0023 \times 10^{3}$ \\
\hline & & Maximum & $3.8265 \times 10^{69}$ & $13.415 \times 10^{13}$ & $1.4319 \times 10^{24}$ \\
\hline \multirow[t]{4}{*}{ F3 } & \multirow{4}{*}{$\begin{array}{l}\text { Shifted Rosenbrock's } \\
\text { Function } \\
f_{3}(x)=\sum_{i=1}^{n}\left(\left[x_{i}+0.5\right]\right)^{2}\end{array}$} & Average & $2.7399 \times 10^{32}$ & $12.121 \times 10^{9}$ & $4.3317 \times 10^{19}$ \\
\hline & & Standard Deviation & $1.0523 \times 10^{33}$ & $11.598 \times 10^{11}$ & $3.9854 \times 10^{20}$ \\
\hline & & Minimum & $0.0161 \times 10^{3}$ & $4.686 \times 10^{2}$ & $0.0082 \times 10^{3}$ \\
\hline & & Maximum & $4.0777 \times 10^{33}$ & $10.032 \times 10^{13}$ & $4.3987 \times 10^{19}$ \\
\hline \multirow[t]{4}{*}{ F4 } & Shifted Rastrigin's Function & Average & $5.2988 \times 10^{44}$ & $6.8166 \times 10^{38}$ & $2.2347 \times 10^{27}$ \\
\hline & \multirow{3}{*}{$f_{4}(x)=\sum_{i=1}^{n}\left[x_{i}^{2}+10 \cos \left(2 \pi x_{i}\right)+10\right]$} & Standard Deviation & $2.9021 \times 10^{45}$ & $7.0025 \times 10^{39}$ & $1.4921 \times 10^{28}$ \\
\hline & & Minimum & $0.0063 \times 10^{3}$ & $1.792 \times 10^{2}$ & $0.0076 \times 10^{3}$ \\
\hline & & Maximum & $1.5896 \times 10^{46}$ & $9.568 \times 10^{41}$ & $2.4682 \times 10^{27}$ \\
\hline \multirow[t]{4}{*}{ F5 } & \multirow{4}{*}{$\begin{array}{l}\text { Shifted Schwefel's Problem with Noise in Fitness } \\
f_{5}(x)=\max \left\{\left|x_{i}\right|, 1 \leq i \leq n\right\}\end{array}$} & Average & $2.2974 \times 10^{34}$ & $5.6982 \times 10^{34}$ & $3.8751 \times 10^{22}$ \\
\hline & & Standard Deviation & $2.2798 \times 10^{35}$ & $6.2784 \times 10^{38}$ & $2.9852 \times 10^{23}$ \\
\hline & & Minimum & $0.0009 \times 10^{3}$ & $0.0561 \times 10^{3}$ & $0.0023 \times 10^{3}$ \\
\hline & & Maximum & $2.2799 \times 10^{36}$ & $5.5862 \times 10^{36}$ & $4.0012 \times 10^{22}$ \\
\hline \multirow[t]{4}{*}{ F6 } & Schwefel's Problem with Global Optimum on Bounds & Average & $3.0414 \times 10^{30}$ & $2.1187 \times 10^{42}$ & $1.8955 \times 10^{43}$ \\
\hline & \multirow{3}{*}{$f_{6}(x)=\sum_{i=1}^{n}\left[100\left(x_{i+1}-x_{i}^{2}\right)^{2}+\left(x_{i}-1\right)^{2}\right]$} & Standard Deviation & $2.5276 \times 10^{31}$ & $1.5182 \times 10^{44}$ & $1.9865 \times 10^{44}$ \\
\hline & & Minimum & $0.0015 \times 10^{3}$ & $0.172 \times 10^{2}$ & $0.0089 \times 10^{3}$ \\
\hline & & Maximum & $2.4682 \times 10^{32}$ & $2.930 \times 10^{45}$ & $2.2219 \times 10^{43}$ \\
\hline \multirow[t]{4}{*}{ F7 } & Shifted Rotated Griewank's Function & Average & $3.4099 \times 10^{33}$ & $11.530 \times 10^{35}$ & $7.6482 \times 10^{34}$ \\
\hline & \multirow{3}{*}{$f_{7}(x)=\sum_{i=1}^{n} i x_{i}^{4}+\operatorname{random}[0,1]$} & Standard Deviation & $2.4053 \times 10^{34}$ & $13.028 \times 10^{36}$ & $5.6214 \times 10^{35}$ \\
\hline & & Minimum & $0.0008 \times 10^{3}$ & $1.406 \times 10^{2}$ & $0.0019 \times 10^{3}$ \\
\hline & & Maximum & $1.8920 \times 10^{35}$ & $11.022 \times 10^{38}$ & $4.5875 \times 10^{34}$ \\
\hline \multirow[t]{4}{*}{ F8 } & Shifted Rotated Ackley's Function with Global Optimum on Bounds & Average & $5.0129 \times 10^{32}$ & $6.321 \times 10^{31}$ & $8.8626 \times 10^{29}$ \\
\hline & \multirow{3}{*}{$f_{8}(x)=\sum_{i=1}^{n}-x_{i} \sin \left(\sqrt{\left|x_{i}\right|}\right)$} & Standard Deviation & $2.2418 \times 10^{33}$ & $5.4213 \times 10^{32}$ & $4.5897 \times 10^{30}$ \\
\hline & & Minimum & $0.0018 \times 10^{3}$ & $2.1235 \times 10^{3}$ & $0.0062 \times 10^{3}$ \\
\hline & & Maximum & $1.0026 \times 10^{34}$ & $8.082 \times 10^{33}$ & $6.9871 \times 10^{29}$ \\
\hline
\end{tabular}

proficient in transient stability establishment. This is accomplished by a metamorphic PDF plus $(1+\mathrm{PI})$ controller, which minimizes the error in the steadystate and at the same time manages speed and system stability. The controller consists of two stages, the 1st stage is a PD controller with filter and the 2nd stage is a 1 plus PI controller. To perform the corrective action ACE is accepted as input by the PDF controller and the output of this is endorsed by the PI controller. The structure of the proposed controller is shown in Fig. 2.
The mathematical expression of the PDF plus $(1+\mathrm{PI})$ controller is given as:

$$
T f_{P D F+(1+P I)}=\left(K_{P}+K_{D}\left(\frac{N s}{N+s}\right)\right)\left(1+K_{P P}+\frac{K_{I}}{s}\right)
$$

As shown, there are different elements of the PDF plus $(1+\mathrm{PI})$ controller, i.e., $\mathrm{K}_{\mathrm{P}}, \mathrm{K}_{\mathrm{I}}, \mathrm{K}_{\mathrm{D}}, \mathrm{K}_{\mathrm{PP}}$ and $\mathrm{N}$. The Area control error $(\mathrm{ACE})$ is input to the controller and the output signal will be the input for the power network 


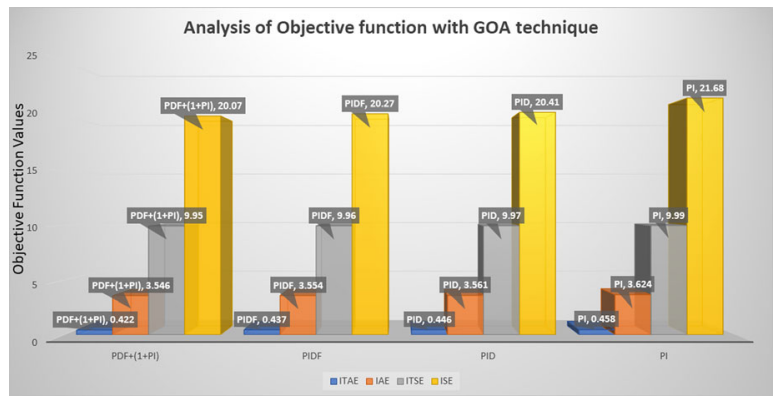

Fig. 4 Study of the different objective functions with GOA

with the addition of changes in tie-line power and frequency.

ACE is the difference between the actual power generation and the scheduled generation with the influence of frequency bias, and is given as:

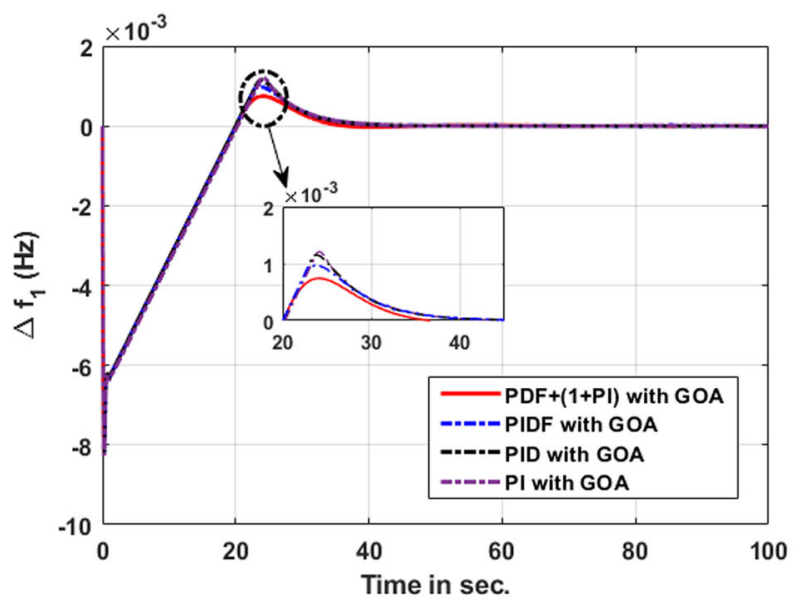

(a)

$$
A C E_{i}=\beta_{i} \Delta F_{i}+\sum_{\substack{j=1 \\ j \neq i}}^{n} \Delta P_{t i e i-j}
$$

\section{Grasshopper optimization algorithm}

The Grasshopper Optimization Algorithm (GOA) is a contemporary multifaceted anatomical method proposed in [25]. The GOA approach is based on the life cycle of the grasshopper, which consists of three stages of egg, nymph and adult going through a process called metamorphosis. Grasshoppers migrate from egg to nymph as sliding cylinders, and then when they migrate from nymph to metamorphosis, they damage crops. This nature is mathematically modeled to form an anatomical optimization technique named GOA. It has two aspects: first, during the investigation it searches for members, and then it

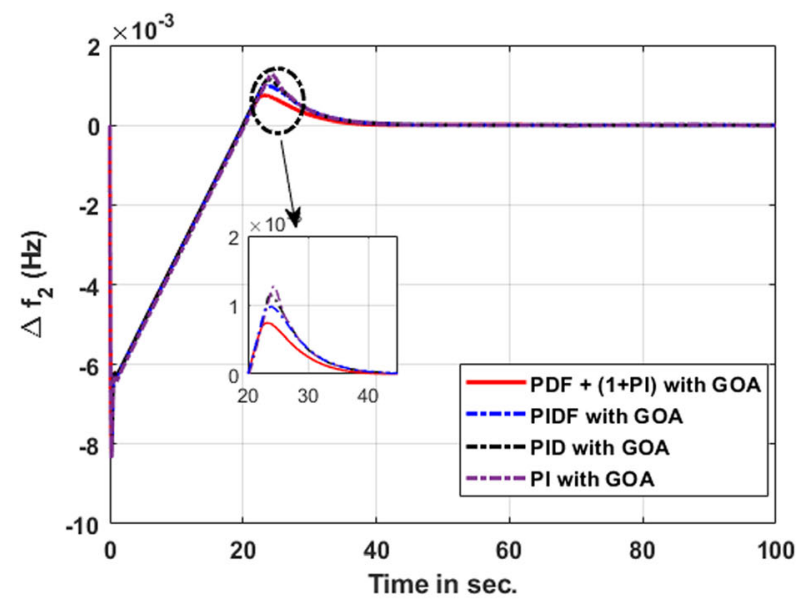

(b)

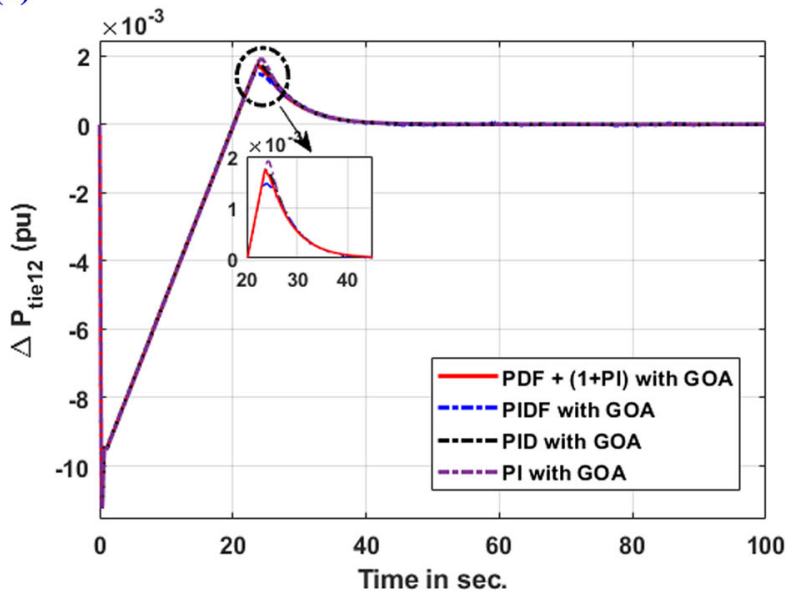

(c)

Fig. 5 Dynamic responses of different GOA optimized controllers with 1\% SLP and IPFC device in each area 
Table 2 Peak deviation and settling time for effectiveness measurement of PDF plus $(1+\mathrm{PI})$ controller

\begin{tabular}{|c|c|c|c|c|c|c|c|c|c|c|c|c|}
\hline \multirow[t]{2}{*}{ Element } & \multicolumn{4}{|c|}{ Peak Overshoot (+) } & \multicolumn{4}{|c|}{ Peak Undershoot (-) } & \multicolumn{4}{|c|}{ Settling Time in seconds } \\
\hline & $\mathrm{PI}$ & PID & PIDF & $\mathrm{PDF}+(1+\mathrm{PI})$ & $\mathrm{PI}$ & PID & PIDF & $\mathrm{PDF}+(1+\mathrm{PI})$ & $\mathrm{PI}$ & PID & PIDF & $\mathrm{PDF}+(1+\mathrm{PI})$ \\
\hline$f_{1}(\mathrm{~Hz})$ & 0.001205 & 0.001184 & 0.000963 & 0.000740 & 0.008266 & 0.007891 & 0.007613 & 0.007415 & 44.65 & 41.25 & 38.34 & 34.22 \\
\hline$\Delta f_{2}(H z)$ & 0.001269 & 0.001163 & 0.000976 & 0.000735 & 0.008362 & 0.008184 & 0.007771 & 0.007567 & 43.71 & 41.95 & 39.39 & 37.07 \\
\hline$\Delta f_{3}(H z)$ & 0 & 0.001 & 7 & 0. & 5 & 02 & 51 & 0 & 44.50 & 42.64 & 40.68 & 38.12 \\
\hline$\Delta P_{t i e-2}(p u)$ & 0.001873 & 0.001718 & 0.001434 & 0.001674 & 0.011169 & 0.010894 & 0.009867 & 0.008423 & 52.58 & 45.31 & 43.22 & 42.68 \\
\hline$\Delta P_{\text {tie2-3 }}(p u)$ & 0.001875 & 0.001693 & 0.001548 & 0.001458 & 0.011421 & 0.011228 & 0.011205 & 0.010127 & 54.88 & 42.39 & 41.17 & 37.84 \\
\hline$\Delta P_{\text {tie3-1 }}(p u)$ & 0.001751 & 0.001697 & 0.001676 & 0.001467 & 0.011308 & 0.011235 & 0.011218 & 0.010113 & 49.81 & 45.45 & 42.22 & 40.96 \\
\hline
\end{tabular}

moves nearby in the exploitation. This ensures the goal is accomplished logically.

The congregate behavior of 'Grasshoppers' is precisely articulated as follows:

$$
X_{m}=S_{m}+G_{m}+A_{m}
$$

where $X_{m}$ is the location of the $m^{\text {th }}$ Grasshopper, $S_{m}$ is the correlation, $G_{m}$ is the gravitational strength on the $\mathrm{m}^{\text {th }}$ Grasshopper, and $\mathrm{A}_{\mathrm{m}}$ is the wind in abeyance. The equation can be upgraded to allow for arbitrary nature as:

$$
X_{m}=r_{1} S_{m}+r_{2} G_{m}+r_{3} A_{m}
$$

where $r_{1}, r_{2}$, and $r_{3}$ are arbitrary coefficients, and

$$
S_{m}=\sum_{\substack{n=1 \\ n \neq m}}^{k} s\left(d_{m n}\right) \widehat{d_{m n}}
$$

where $d_{m n}$ is the gap among the $m^{\text {th }}$ and $n^{\text {th }}$ Grasshoppers, $d_{m n}=\left|x_{n}-x_{m}\right|, s$ is the function of collective forces, and $\widehat{d_{m n}}=\frac{x_{n}-x_{m}}{d_{m n}}$ is a unit vector from the $m^{\text {th }}$ to $\mathrm{n}^{\text {th }}$ Grasshoppers.

The $\mathrm{s}$ function for the collective forces (dislike and like) is given as:

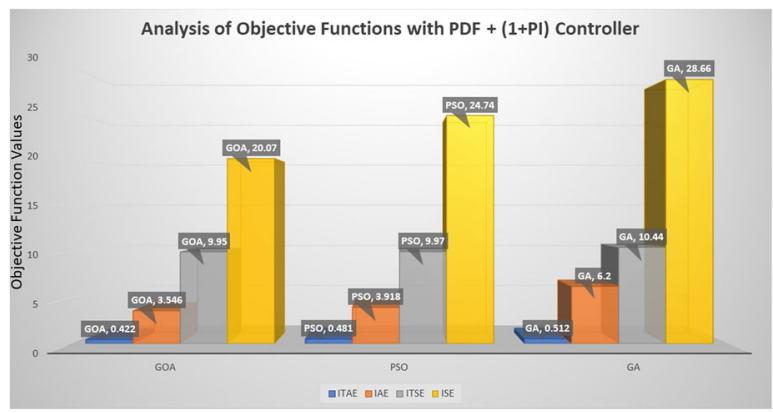

Fig. 6 Study of the objective function with PDF plus (1 + PI)

$$
s(r)=f e^{-r / l}-e^{-r}
$$

where $\mathrm{f}$ is the potential of likeness and $\mathrm{l}$ is the detachment of likeness force.

The $\mathrm{G}$ factor in (8) is evaluated as:

$$
G_{i}=-g \widehat{e_{g}}
$$

where $g$ is the gravitational force constant and $\widehat{e_{g}}$ is a unity vector focused on along the earth's center.

The A factor in (8) is evaluated as:

$$
A_{m}=u \widehat{e_{w}}
$$

where $\mathrm{u}$ is a constant drift and $\widehat{\mathrm{e}_{\mathrm{w}}}$ is a unity vector for the wind course.

Replacing S, G, and A in (8) yields:

$$
X_{m}=\sum_{\substack{n=1 \\ n \neq m}}^{k} s\left(\left|x_{n}-x_{m}\right|\right) \frac{x_{n}-x_{m}}{d_{m n}}-g \widehat{e_{g}}+u \widehat{e_{w}}
$$

where $\mathrm{n}$ is the number of grasshoppers.

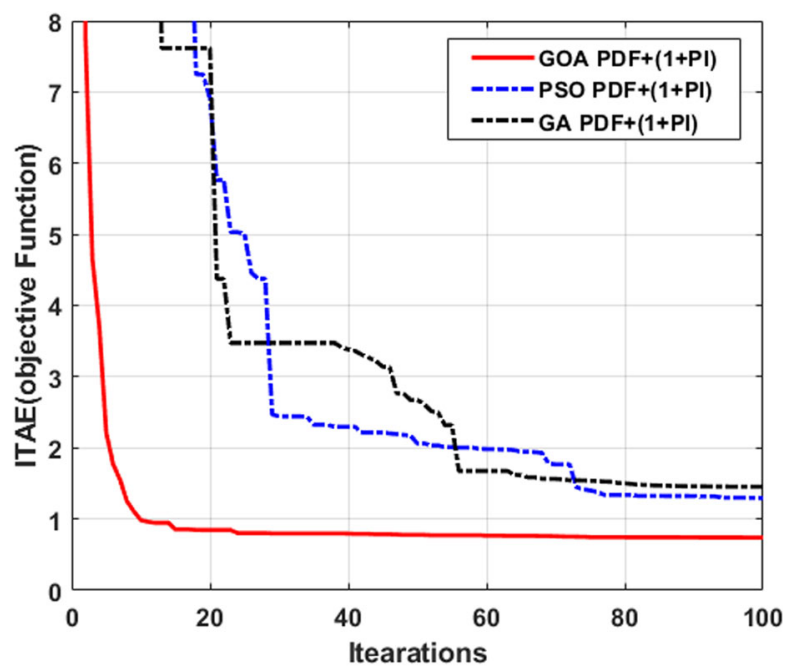

Fig. 7 Convergence curves for GA, PSO \& GOA 


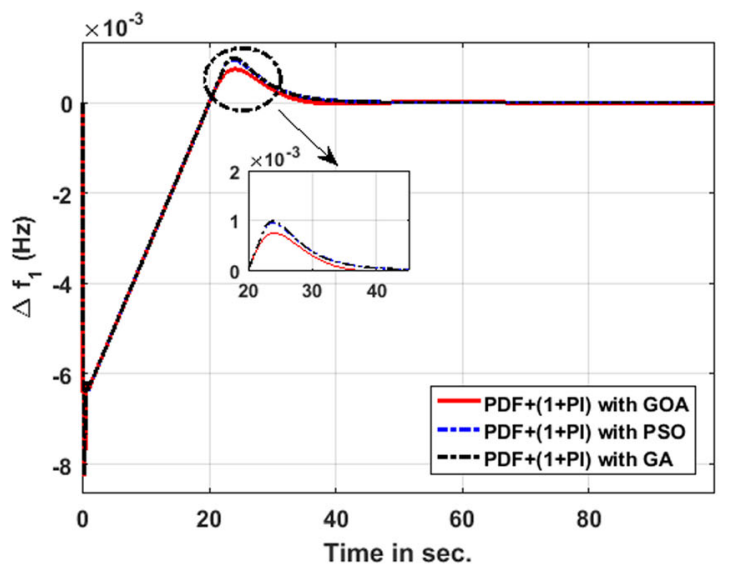

(a)

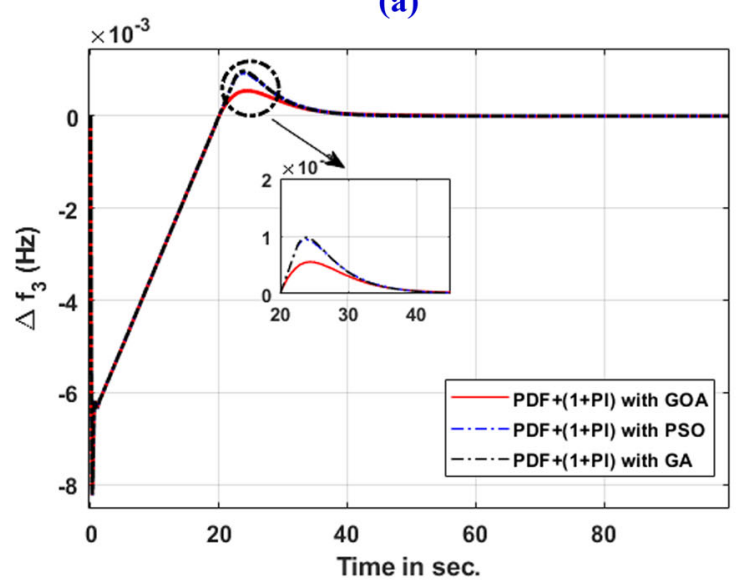

(b)

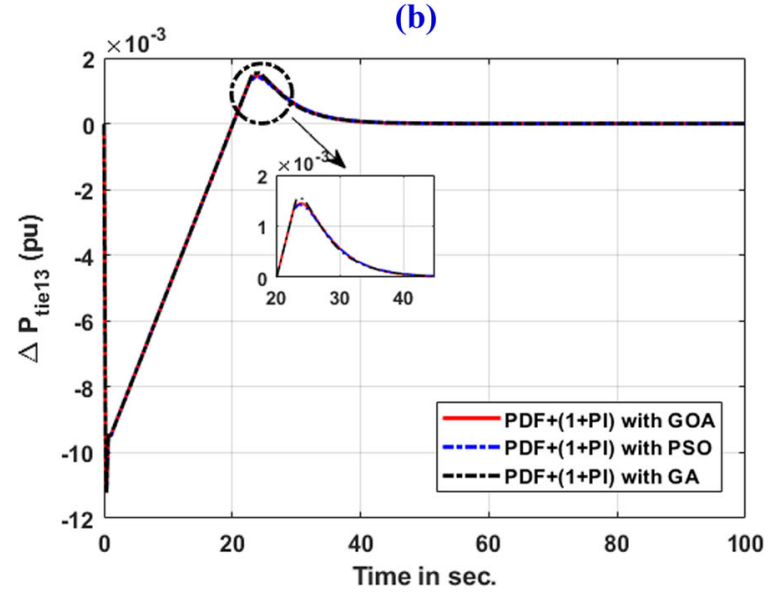

(c)

Fig. 8 Dynamic responses of different techniques of GOA, PSO and GA optimized with PDF plus $(1+\mathrm{PI})$, with $1 \%$ SLP and IPFC device in each area
For optimization on the global horizon, (13) is altered as:

$$
X_{m}{ }^{d}=c\left(\sum_{\substack{n=1 \\ n \neq m}}^{k} c \frac{u b_{d}-l b_{d}}{2} s\left(\left|x_{n}{ }^{d}-x_{m}{ }^{d}\right|\right) \frac{x_{n}-x_{m}}{d_{m n}}\right)+\widehat{T}_{d}
$$

where $u b_{d}$ is the $D^{\text {th }}$ aspect upper bound, $l_{d}$ is the $D^{\text {th }}$ aspect lower bound, $\widehat{T_{d}}$ is the $D^{\text {th }}$ aspect of the objective bound, and $\mathrm{c}$ is a declining factor to minimize the comfort zone, dislike zone and like zone. Based on current place, GOA unceasingly updates the location of an investigation agent, global optimum and the location of all other investigation agents.

The comfort zone reduces, and coefficient $\mathrm{c}$ is proportional to the number of iterations and is evaluated as:

$$
c=c \max -l \frac{c \max -c \min }{L}
$$

where cmax is the max value, $\mathrm{cmin}$ is the min value, 1 indicates the current iteration, and $\mathrm{L}$ is the number of iterations.

GOA is initiated by forming a collection of random results, and searching representatives upgrade their location at each iteration by (13). At the termination of every iteration, the finest marked location is upgraded. In addition, factor c is evaluated using (14) and the linearization of gaps among grasshoppers is carried out in every repetition. Adaptation is made iteratively until the final criterion is matched, and the global optimum comes out as the best approximation returned finally by the position and fitness of the best target. The flowchart of the GOA technique is given in Fig. 3.

\subsection{Statistical analysis of GOA}

Statistical analysis of the proposed PDF plus $(1+\mathrm{PI})$ controller with different algorithms of GOA, PSO and GA optimized for standard deviation, min, max and average values of fitness function is presented in Table 1. It is clear from Table 1 that functions F5, F6, F7, and F8 for GOA give good average results, and function $\mathrm{F} 6$ with $\mathrm{SD}=2.5276$ $\mathrm{X} 10^{31}$ provides the best results in all respects out of the 23 predefined objective functions. Functions F2 with $\mathrm{SD}=$ $1.428 \times 10^{25}$ and F5 with $\mathrm{SD}=6.2784 \times 10^{38}$ provide the best results in the cases of GA and PSO, respectively.

\section{Results and discussions}

The study is carried out using MATLAB R2019a, while the multi-thermal power system model is 
Table 3 Peak deviation and settling time for effectiveness measurement of GOA with PDF plus (1 + PI) controller

\begin{tabular}{|c|c|c|c|c|c|c|c|c|c|}
\hline \multirow[t]{2}{*}{ Element } & \multicolumn{3}{|c|}{ Peak Overshoot (+) } & \multicolumn{3}{|c|}{ Peak Undershoot (-) } & \multicolumn{3}{|c|}{ Settling Time in seconds } \\
\hline & $\overline{\mathrm{GA}}$ & PSO & GOA & $\overline{\mathrm{GA}}$ & PSO & GOA & $\overline{\mathrm{GA}}$ & PSO & GOA \\
\hline$\Delta f_{1}(H z)$ & 0.000983 & 0.000949 & 0.000740 & 0.008227 & 0.007562 & 0.007415 & 46.13 & 42.89 & 34.22 \\
\hline$\Delta f_{2}(H z)$ & 0.001013 & 0.000948 & 0.000735 & 0.008228 & 0.007643 & 0.007567 & 47.16 & 43.91 & 37.07 \\
\hline$\Delta f_{3}(H z)$ & 0.000974 & 0.000912 & 0.000551 & 0.008225 & 0.007998 & 0.006845 & 46.37 & 42.61 & 38.12 \\
\hline$\Delta P_{t i e 1-2}(p u)$ & 0.001832 & 0.001698 & 0.001674 & 0.011228 & 0.010935 & 0.008423 & 44.67 & 43.57 & 42.68 \\
\hline$\Delta P_{t i e 2-3}(p u)$ & 0.001536 & 0.001572 & 0.001458 & 0.011231 & 0.010564 & 0.010127 & 42.16 & 40.28 & 37.84 \\
\hline$\Delta P_{\text {tie3-1 }}(p u)$ & 0.001547 & 0.001422 & 0.001467 & 0.011159 & 0.011032 & 0.010113 & 46.02 & 41.53 & 40.96 \\
\hline
\end{tabular}

developed in SIMULINK with the reheat turbine, GRC and PDF plus $(1+\mathrm{PI})$ controller. The GOA, PSO and GA programs are in script-file and functionfile of MATLAB R2019a. The exploration is carried by 100 agents and 100 iterations are reserved for entire investigations. The efficacy authentication of the different objective functions is carried out by setting each control area with $1 \%$ SLP at $\mathrm{t}=0 \mathrm{~s}$.

\subsection{Effectiveness of PDF plus $(1+\mathrm{PI})$ controller}

In this segment, the 3-area thermal power network fitted with reheat turbine, GRC and IPFC in each control area is examined by various controllers such as PI, PID, PIDF and PDF plus $(1+$ PI) optimized by the GOA technique. The obtained controller gains are as follows:

PI controller in each area:

$$
\begin{aligned}
& K_{P 1}=0.0169 ; K_{P 2}=0.3187 ; K_{P 3}=1.9829 ; \\
& K_{I 1}=1.8142 ; K_{I 2}=1.9035 ; K_{I 3}=1.6172 ;
\end{aligned}
$$

PID controller in each area:

$$
\begin{aligned}
& K_{P 1}=-0.0619 ; K_{P 2}=-0.0232 ; K_{P 3}=1.9963 ; \\
& K_{D 1}=-0.0032 ; K_{D 2}=0.0027 ; K_{D 3}=0.1427 \\
& K_{I 1}=1.9541 ; K_{I 2}=1.9375 ; K_{I 3}=1.6514 ;
\end{aligned}
$$

PIDF controller in each area:

$$
\begin{aligned}
& K_{P 1}=0.4724 ; K_{P 2}=0.7055 ; K_{P 3}=0.7323 \\
& K_{D 1}=0.0512 ; K_{D 2}=0.0138 ; K_{D 3}=0.2113 \\
& K_{I 1}=1.8212 ; K_{I 2}=1.9375 ; K_{I 3}=1.614 ; \\
& N_{1}=33.8127 ; N_{2}=74.9604 ; N_{3}=2.5760
\end{aligned}
$$

PDF plus $(1+\mathrm{PI})$ controller in each area:

$$
\begin{aligned}
& K_{P 1}=-1.9255 ; K_{P 2}=1.8659 ; K_{P 3}=1.9547 ; \\
& K_{P P 1}=-1.8694 ; K_{P P 2}=0.3766 ; K_{P P 3}=0.1075 ; \\
& K_{D 1}=0.0071 ; K_{D 2}=0.1114 ; K_{D 3}=0.0045 ; \\
& K_{I 1}=-1.9161 ; K_{I 2}=1.9219 ; K_{I 3}=1.9372 ; \\
& N_{1}=48.9384 ; N_{2}=0.0720 ; N_{3}=48.1291 ;
\end{aligned}
$$

The comparative analysis of different objective functions with the various controllers with the GOA algorithm is shown in Fig. 4. Compared to PIDF, PID and PI, the improvements in the ITAE error with the proposed GOA tuned PDF plus $(1+\mathrm{PI})$ controller are $3.43 \%, 5.38 \%$ and $7.86 \%$, respectively.

The dynamic behavior of the power system frequency and tie-line power for each controller is compared in Fig. 5(a)-(c). Performance indices such as the maximum overshoot and undershoot, and settling time of the dynamic responses, are given in Table 2. From Fig. 5 and Table 2, it is evident that the proposed PDF plus $(1+\mathrm{PI})$ controller is better than the classical PI, PID and PIDF controllers with lowest settling time of $34.22 \mathrm{~s}\left(\Delta \mathrm{f}_{1}\right)$ and peak fluctuations.

\subsection{Effectiveness of the GOA algorithm}

In this section, the effectiveness of the structural algorithm-based GOA method is verified with the proposed PDF plus $(1+\mathrm{PI})$ controller. The thermal power system network is fitted with the IPFC controller in each area, while GRC is set at 3\% and all SLP are fixed to $1 \%$. Figure 6 shows the fitness of the best objective function algorithm, with GOA optimized PDF plus (1+PI) controller with ITAE value $0.422 \times 10-2$ having the lowest among the entire statistical data.

Compared to PSO and GA, the improvements in the ITAE error with the proposed GOA tuned PDF plus $(1+$ PI) controller are $12.26 \%$ and $17.57 \%$, respectively. Figure 7 provides complete information regarding the convergence of fitness function (ITAE) with PDF plus $(1+\mathrm{PI})$ controller for GOA, PSO and GA techniques. The dynamic frequency stabilization and tie-line power flow is shown in Fig. 8(a)-(c) and Table 3. The GOA method shows performance superior to that of GA and PSO methods with the same setting and strategy.

\subsection{Effectiveness of several FACTS devices}

In this section, four FACTS devices, i.e., TCPS, SSSC, TCSC, and IPFC are tested in the 3-area thermal power 


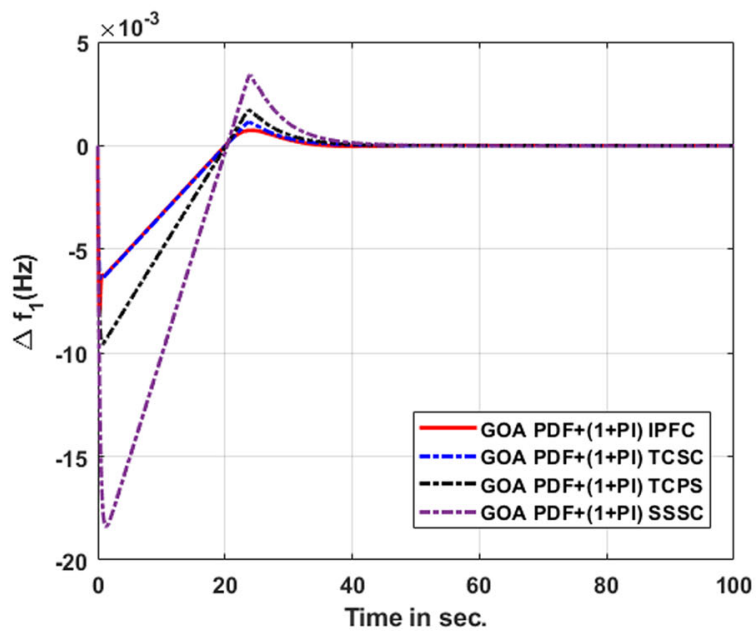

(a)

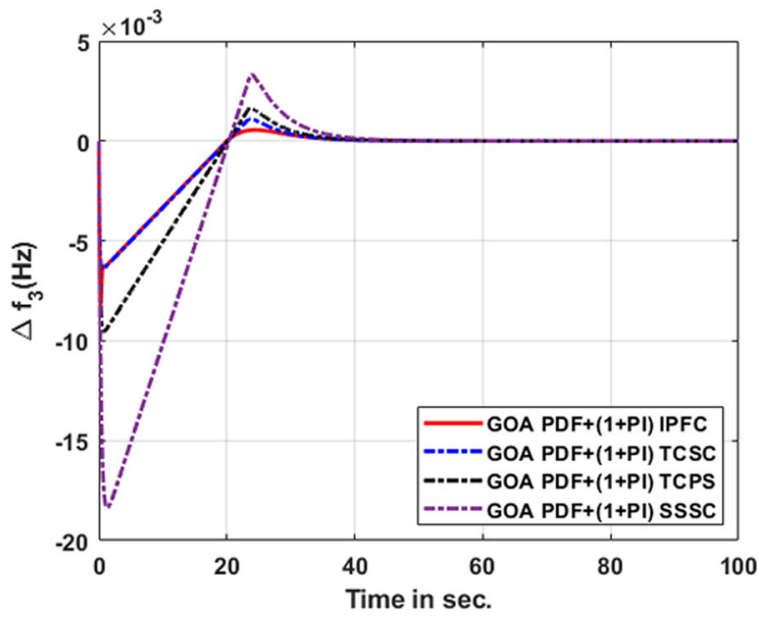

(c)

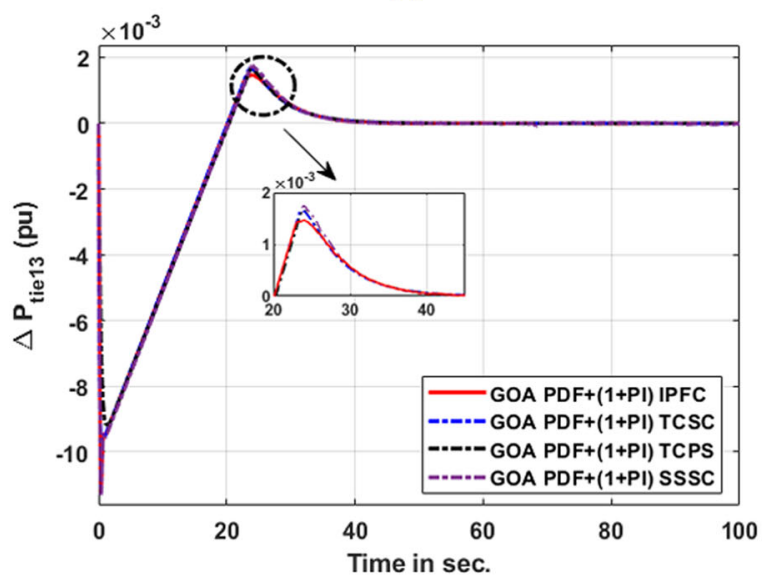

(e)

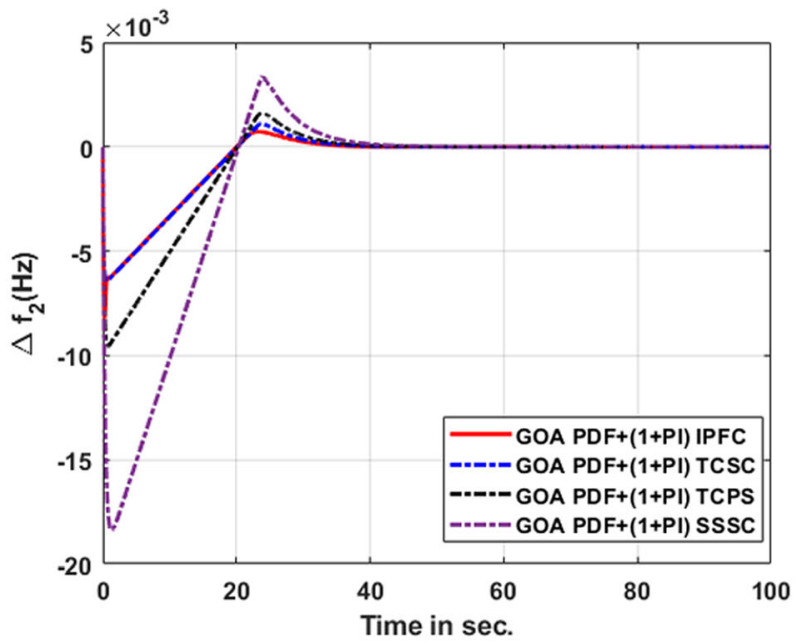

(b)

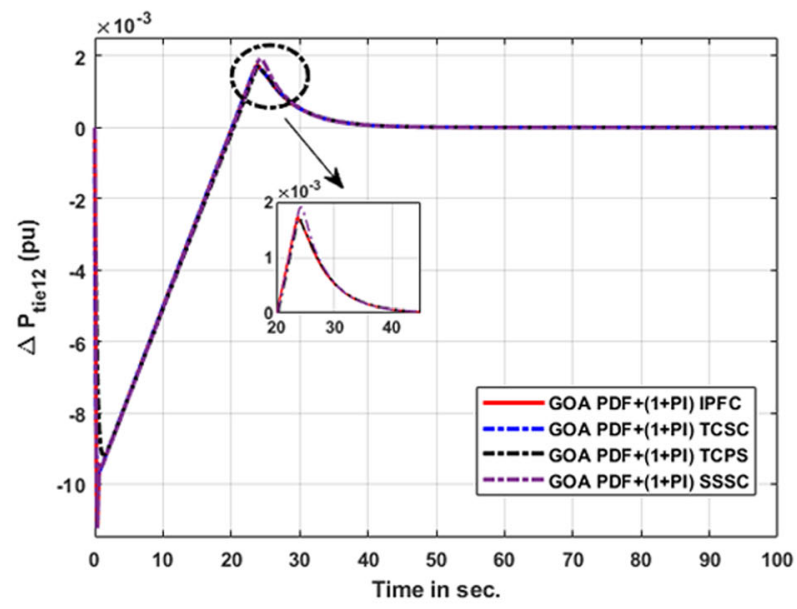

(d)

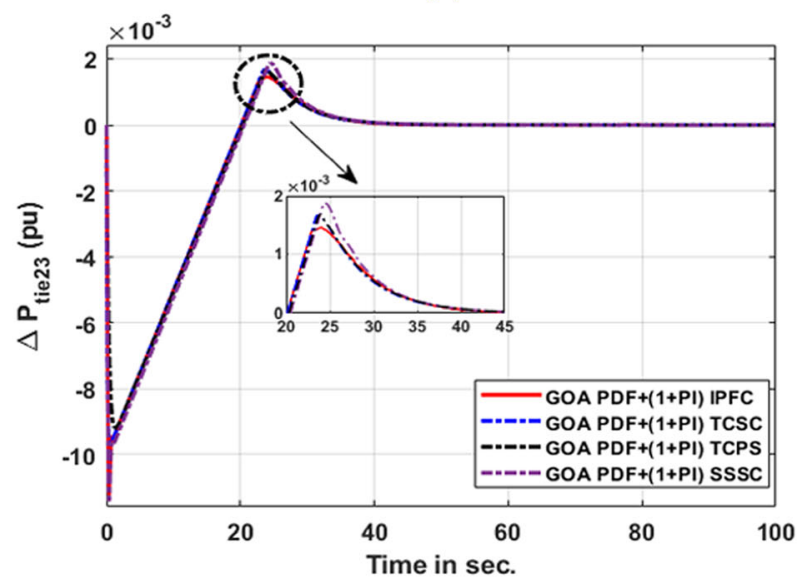

(f)

Fig. 9 Dynamic responses of FACTS devices with GOA optimized PDF+(1 + PI) controller and 1\% SLP 
Table 4 Peak deviation and settling time for effectiveness measurement of FACTS devices

\begin{tabular}{|c|c|c|c|c|c|c|c|c|c|c|c|c|}
\hline \multirow[t]{2}{*}{ Element } & \multicolumn{4}{|c|}{ Peak Overshoot (+) } & \multicolumn{4}{|c|}{ Peak Undershoot (-) } & \multicolumn{4}{|c|}{ Settling Time in seconds } \\
\hline & SSSC & TCPS & TCSC & IPFC & SSSC & TCPS & TCSC & IPFC & SSSC & TCPS & TCSC & IPFC \\
\hline & 303 & 0016 & 001 & Oחת & 018 & 0.0095 & 0.006 & 000 & 45.70 & 41.39 & 39.48 & 34 \\
\hline$f_{2}(H z)$ & 03345 & .001582 & 0.001114 & 0.000735 & 18384 & 0.009535 & 0.006459 & 0.007567 & 45.83 & 43.09 & 38.78 & 37. \\
\hline$f_{3}(\mathrm{~Hz})$ & 0.003297 & 0.001656 & 0.001104 & 0.000551 & 0.018382 & 0.009555 & 0.006431 & 0.006845 & 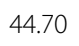 & 2 & 28 & 3 \\
\hline$P_{\text {tie1-2 }}(p u)$ & .001965 & 0.001788 & 0.001699 & 0.001674 & 0.011174 & 0.010781 & 0.009131 & 0.008423 & 46.58 & 43.38 & 41.91 & 42 \\
\hline$\Delta P_{\text {tie2-3 }}(p u)$ & 01898 & .001670 & 0.001623 & 0.001458 & 1426 & 0.010368 & 0.010293 & 0.010127 & 44.88 & 42.62 & 41.31 & 37 \\
\hline$P_{\text {tie3-1 }}(p u)$ & 0.001758 & 0.001689 & 0.001661 & 0.001467 & 0.011223 & 0.010846 & 0.010547 & 0.010113 & 47.22 & 44.36 & 41.76 & 40 \\
\hline
\end{tabular}

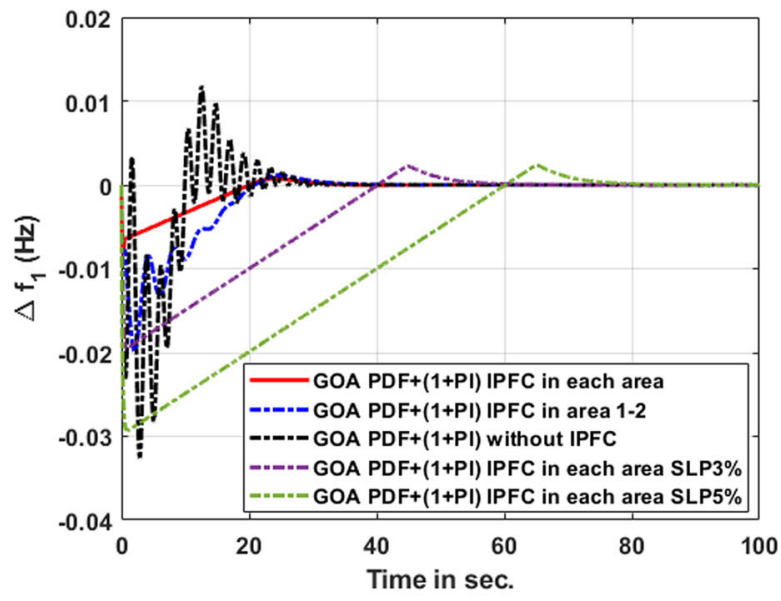

(a)

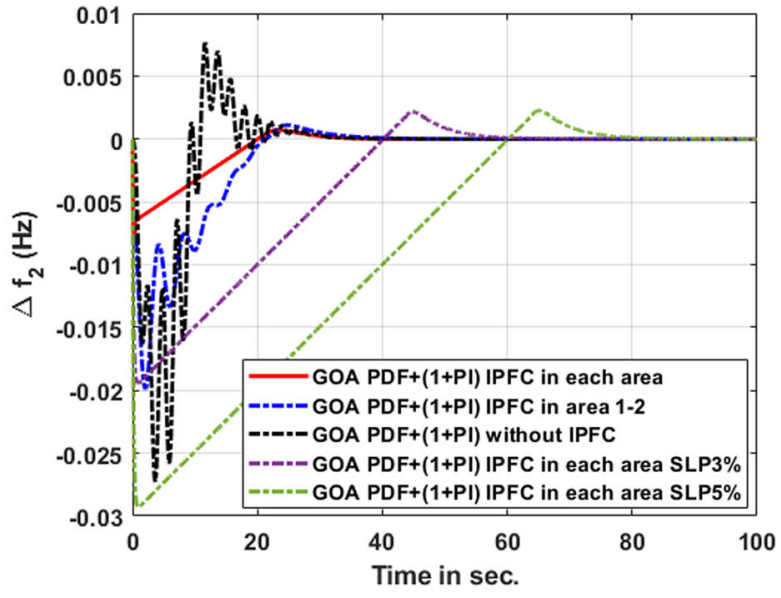

(b)

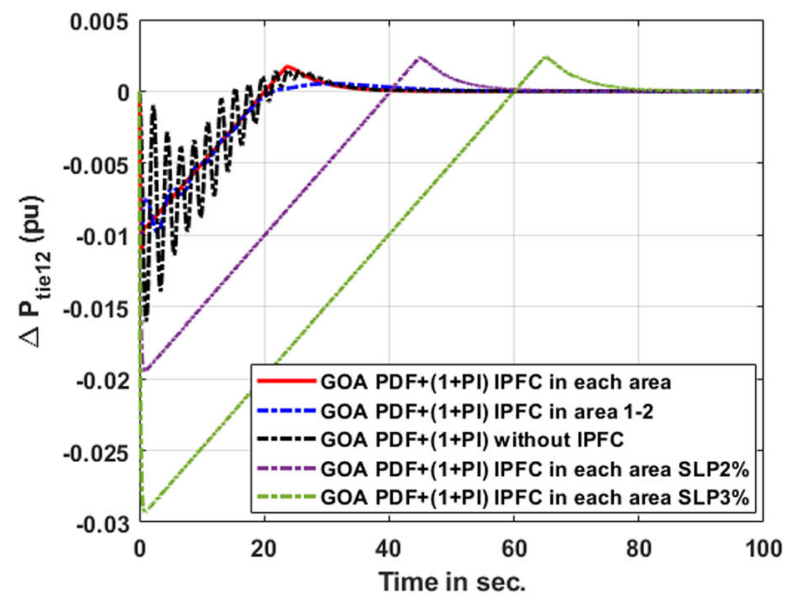

(c)

Fig. 10 Dynamic responses of IPFC with different locations and SLP values 
Table 5 Peak deviation and settling time for GOA optimized PDF plus (1 + PI) controller with IPFC and different SLP values

\begin{tabular}{|c|c|c|c|c|c|c|c|c|c|}
\hline \multirow[t]{2}{*}{ Condition } & \multicolumn{3}{|c|}{ Peak Overshoot (+) } & \multicolumn{3}{|c|}{ Peak Undershoot (-) } & \multicolumn{3}{|c|}{ Settling Time in seconds } \\
\hline & $\Delta f_{1}(\mathrm{~Hz})$ & $\Delta f_{2}(H z)$ & $\Delta P_{\text {tie 1-2 }}(p u)$ & $\Delta f_{1}(\mathrm{~Hz})$ & $\Delta f_{2}(H z)$ & $\Delta P_{\text {tie 1-2 }}(p u)$ & $\Delta f_{1}(H z)$ & $\Delta f_{2}(H z)$ & $\Delta P_{\text {tie 1-2 }}(p u)$ \\
\hline Without IPFC & 0.011598 & 0.007540 & 0.001431 & 0.032582 & 0.026905 & 0.016016 & 38.73 & 3914 & 49.41 \\
\hline IPFC in 1-2 & 0.001170 & 0.001118 & 0.000647 & 0.019762 & 0.019764 & 0.011305 & 35.96 & 38.43 & 39.83 \\
\hline IPFC in 1-2-3 & 0.000740 & 0.000735 & 0.000551 & 0.007415 & 0.007567 & 0.006845 & 34.22 & 37.07 & 38.12 \\
\hline SLP 3\% & 0.002273 & 0.002125 & 0.002308 & 0.019367 & 0.019417 & 0.019322 & 58.15 & 56.92 & 58.12 \\
\hline SLP 5\% & 0.002358 & 0.002244 & 0.002399 & 0.029284 & 0.029264 & 0.029257 & 76.19 & 77.43 & 78.45 \\
\hline
\end{tabular}

system with PDF plus $(1+\mathrm{PI})$ controller optimized by GOA technique.

The dynamic responses of frequency deviation and power exchange across the tie-line are given in Fig. 9(a)-(f), while the performance indices are given in Table 4. From this analysis, it is noted that IPFC gives improved dynamic response (peak overshoot and undershoot and settling time) over other proposed FACTS devices. Compared to SSSC, TCPS and TCSC, the improved settling times of frequency deviation $\Delta \mathrm{f}_{1}$ with IPFC and the proposed GOA tuned PDF plus $(1+\mathrm{PI})$ controller are $25.12 \%$, $17.32 \%$ and $13.32 \%$, respectively, while for $\Delta f_{2}$, they are $19.11 \%, 13.97 \%$ and $4.40 \%$, respectively. For $\Delta f_{3}$, the corresponding settling time improvements are $14.72 \%, 12 \%$ and $5.36 \%$, respectively. For $\Delta \mathrm{P}_{\text {tie } 1-2}$, the improved settling times of frequency deviation with IPFC compared to SSSC, TCPS and TCSC are $10.02 \%, 3.38 \%$ and $1.8 \%$, respectively, while the corresponding respective improvements are $15.68 \%$, $11.21 \%$ and $8.39 \%$ for $\Delta \mathrm{P}_{\text {tie2-3 }}$, and $13.25 \%, 7.66 \%$ and $1.91 \%$ for $\Delta \mathrm{P}_{\text {tie3-1 }}$.

\subsection{Effectiveness of IPFC at a different location with SLP} In this section, the multi-thermal power system network is tested with different locations of IPFC. It is also verified with hikes in SLP of $3 \%$ and $5 \%$ for the proposed controller and GOA technique. This allows examination of the robustness of the network when there is an uncertain nonlinearity, something that frequently occurs in a power system network.

The dynamic responses for GOA-optimized PDF plus $(1+\mathrm{PI})$ controller for an IPFC enabled AGC system is shown in Fig. 10(a)-(c) with different locations of IPFC and SLP values. The performance attributes are given in Table 5. From these, it can be concluded that the IPFC with each area stabilizes the frequency and limits the oscillation of the power flow.

\subsection{Sensitivity analysis}

In this section, sensitivity analysis is carried out for the proposed GOA optimized PDF plus $(1+\mathrm{PI})$ controller for the IPFC-enabled AGC system. The optimum controller gains are evaluated at nominal loading conditions with $1 \%$ SLP to the wide variation of system parameters. The GOA runs for each possibility of system parameter setting and with tuned parameters system performance index are evaluated. The dynamic response control indices are given in Table 6 . The controller parameters are quite close to each other which validates the robustness of the complete framework as the proposed method. From every aspect it exhibits an effective response in every possible condition.

Table 6 Peak deviation \& Settling time for GOA optimized PDF plus (1 + PI) controller with different loading conditions

\begin{tabular}{|c|c|c|c|c|c|c|c|c|c|}
\hline \multirow{2}{*}{$\begin{array}{l}\text { Loading } \\
\text { Condition }\end{array}$} & \multicolumn{3}{|c|}{ Peak Overshoot (+) } & \multicolumn{3}{|c|}{ Peak Undershoot (-) } & \multicolumn{3}{|c|}{ Settling Time in seconds } \\
\hline & $\Delta f_{1}(H z)$ & $\Delta f_{2}(H z)$ & $\Delta P_{\text {tie1-2 }}(p u)$ & $\Delta f_{1}(H z)$ & $\Delta f_{2}(H z)$ & $\Delta P_{\text {tie1-2}}(p u)$ & $\Delta f_{1}(H z)$ & $\Delta f_{2}(H z)$ & $\Delta P_{\text {tie1-2}}(p u)$ \\
\hline Nominal & 0.000740 & 0.000735 & 0.000551 & 0.007415 & 0.007567 & 0.006845 & 34.22 & 37.07 & 38.12 \\
\hline$+25 \%$ & 0.001748 & 0.001654 & 0.001726 & 0.009492 & 0.009536 & 0.009445 & 41.92 & 41.74 & 42.20 \\
\hline$-25 \%$ & 0.001600 & 0.001611 & 0.001633 & 0.009544 & 0.009483 & 0.009418 & 41.53 & 40.91 & 41.53 \\
\hline$+50 \%$ & 0.002308 & 0.002278 & 0.002236 & 0.009575 & 0.009551 & 0.009554 & 42.02 & 41.89 & 42.23 \\
\hline$-50 \%$ & 0.001582 & 0.001576 & 0.001586 & 0.009531 & 0.009548 & 0.009493 & 40.98 & 41.48 & 41.84 \\
\hline$+75 \%$ & 0.001844 & 0.001802 & 0.001852 & 0.009551 & 0.009475 & 0.009548 & 41.23 & 41.96 & 42.39 \\
\hline$-75 \%$ & 0.001485 & 0.001553 & 0.001513 & 0.009547 & 0.009546 & 0.009557 & 40.58 & 40.35 & 41.02 \\
\hline
\end{tabular}




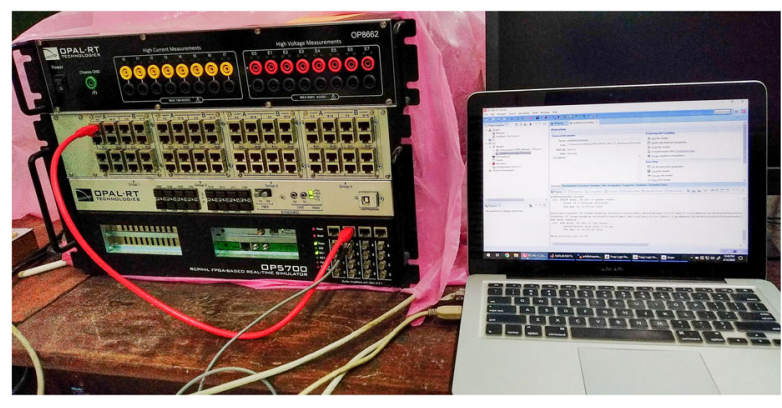

Fig. 11 OPAL-RT OP5700 RCP/HIL FPGA real-time simulator

\subsection{Validation by OP5700 RCP/HIL FPGA real-time simulator}

The OPAL-RT OP5700 RCP/HIL FPGA real-time simulator is shown in Fig. 11 which is used for realtime validation of the proposed research. This is performed for practical feasibility testing. The OPALRT considers the delay and error nonlinearity disturbances which inherently exist but are neglected in conventional off-line simulations [26]. The OPAL-RT allows researchers to authenticate their work in realtime irrespective of complexity. The important features of OPAL-RT are code parallelization, Simulink integration, customizable dashboard, communication protocols and I/O flexibility. The steps of real-time validation include the initialization of the Simulink model via OPAL-RT lab, the transformation of the model into RT application, running the model using multiple cores and finally data acquisition using the graphical interface. The frequency deviation $\left(\Delta \mathrm{f}_{1}\right)$ and tie-line power response $\left(\Delta \mathrm{P}_{\text {tie }} 1-2\right)$ from MATL
AB/SIMULINK and OPAL-RT based Real-Time Simulator (RTS) are shown in Fig. 12(a) and (b). It can be seen that the MATLAB/SIMULINK results match well with those from OPAL-RT real-time simulation.

\section{Conclusion}

A 3-area thermal unit fitted with a reheat turbine is considered in this paper. The Grasshopper optimization algorithm is used in AGC to optimize the PI, PID, PIDF and the proposed PDF plus $(1+\mathrm{PI})$ controllers. First, statistical analysis is carried out to evaluate the effectiveness of GOA in test functions. Several FACTS devices such as SSSC, TCPS, TCSC and IPFC in association with PDF plus $(1+\mathrm{PI})$ optimized by GOA in AGC 3-area systems are tested. Improvements in the ITAE error with the proposed GOA tuned PDF plus $(1+\mathrm{PI})$ controller compared to the PIDF, PID and PI are $3.43 \%, 5.38 \%$ and $7.86 \%$, respectively. The effectiveness of GOA is justified by comparing the dynamic responses with GA and PSO, where respective improvements of $12.26 \%$ and $17.57 \%$ in the ITAE error with the proposed GOA tuned PDF plus $(1+\mathrm{PI})$ controller are achieved. It is also observed that the IPFC gives improved dynamic response (peak overshoot and undershoot, and settling time) in comparison with other considered FACTS devices.

The robustness of the proposed strategy is estimated by various sensitivity analyses. Dynamic behaviors due to different SLP and loading conditions are compared and sensitivity analysis reveals that a GOA-tuned PDF plus $(1+$ PI) controller-fitted IPFC offers robustness in all respects. Finally, the proposed GOA-tuned PDF plus $(1+\mathrm{PI})$ controller fitted IPFC approach is authenticated by OPAL-RT based simulations in a real-time environment.

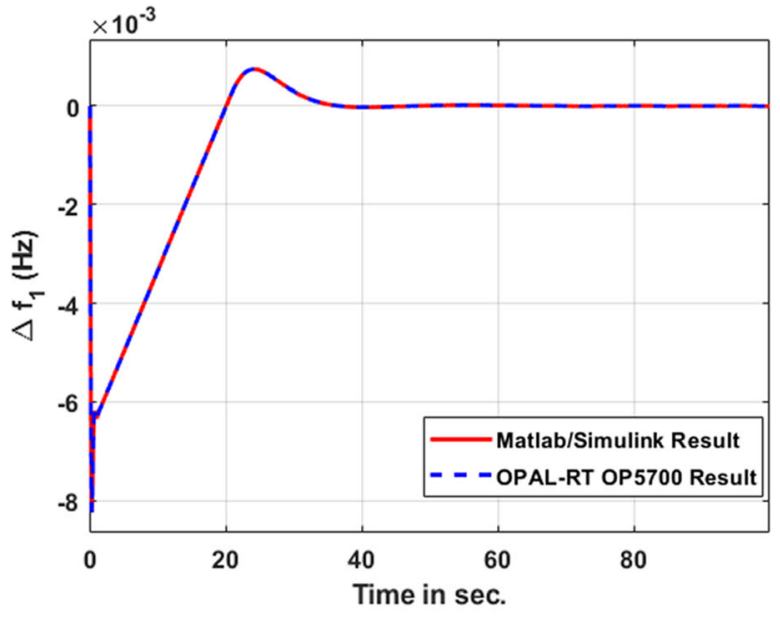

(a)

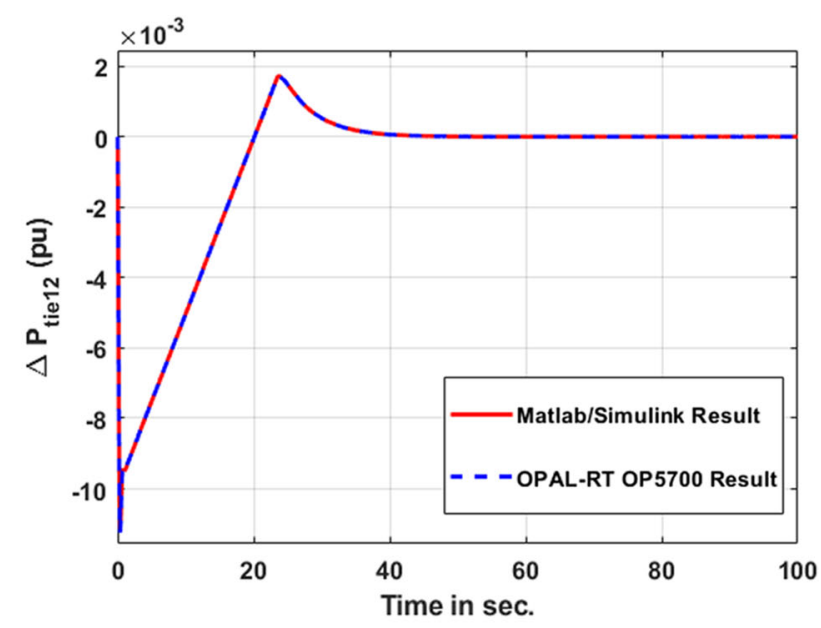

(b)

Fig. 12 OPAL-RT OP5700 RCP/HIL FPGA real-time simulator vs MATLAB/SIMULINK results 


\section{Appendix}

Table 7 Nominal parameters of the system: system frequency $f=60 \mathrm{~Hz}$, Tgi $=0.08 \mathrm{~s}$, Tti $=0.3 \mathrm{~s} ; \mathrm{Tri}=10 \mathrm{~s} ; \mathrm{Kri}=0.5 ; \mathrm{Kpi}=120 \mathrm{~Hz} / \mathrm{pu}$ $\mathrm{MW} ; \mathrm{Tpi}=20 \mathrm{~s} ; \mathrm{T} 12=0.086 \mathrm{pu} \mathrm{MW/rad} ; \mathrm{Hi}=\mathrm{s} ; \mathrm{Di}=8.33 \mathrm{X} 10-3 \mathrm{pu} \mathrm{MW/Hz;} \beta \mathrm{Bi}=0.425 \mathrm{pu} \mathrm{MW/Hz;} \mathrm{Ri}=2.4 \mathrm{pu} \mathrm{Hz} / \mathrm{MW} ;$ loading = 50\%; TSSSC $=0.03 \mathrm{~s} ; \mathrm{KSSSC}=0.1802 ; \mathrm{K} \varphi=1.5 \mathrm{rad} / \mathrm{Hz} ; \mathrm{TPS}=0.1 \mathrm{~s} ; \mathrm{TTCSC}=0.015 \mathrm{~s} ; \mathrm{TIPFC}=0.01 \mathrm{~s}$

\section{Terminology}

\begin{tabular}{|c|c|}
\hline i & Control area number i $(1,2,3)$ \\
\hline$m, n$ & Grasshopper index \\
\hline$x_{m}$ & location of $\mathrm{m}^{\text {th }}$ Grasshopper \\
\hline$S_{m}$ & correlation \\
\hline$G_{m}$ & gravitational strength on the $\mathrm{m}^{\text {th }}$ Grasshopper \\
\hline$A_{m}$ & wind abeyance \\
\hline C & Coefficient of the comfort zone \\
\hline $\mathrm{K}_{\mathrm{sSSC}}$ & SSSC gain \\
\hline $\mathrm{T}_{\mathrm{SSC}}$ & SSSC time constant \\
\hline $\mathrm{T}_{\mathrm{TCPS}}$ & TCPS time constant \\
\hline$K_{\varphi}$ & TCPS gain \\
\hline$\Delta \varphi$ & phase-shifting angle \\
\hline $\mathrm{T}_{\mathrm{TCSC}}$ & TCSC time constant \\
\hline $\mathrm{T}_{\text {IPFC }}$ & IPFC time constant \\
\hline $\mathrm{H}_{\mathrm{i}}$ & inertia constant of control area i (s) \\
\hline$\Delta \mathrm{P}_{\mathrm{Li}}$ & load increments in (p.u) \\
\hline$\Delta \mathrm{P}_{\mathrm{gi}}$ & generation increments in (p.u) \\
\hline$D_{i}$ & $\Delta \mathrm{P}_{\mathrm{Li}} / \Delta f_{\mathrm{i}}(\mathrm{pu} / \mathrm{Hz})$ \\
\hline$T_{12}, T_{23}, T_{13}$ & synchronizing factors \\
\hline $\mathrm{R}_{\mathrm{i}}$ & speed regulation factor of control area i ( $\mathrm{Hz} / \mathrm{pu} \mathrm{MW})$ \\
\hline$T_{g i}$ & the time constant of reheat governor control area i (s) \\
\hline $\mathrm{K}_{\mathrm{ri}}$ & reheat coefficient of control area i \\
\hline$T_{\text {ri }}$ & Reheat time constant of area i (s) \\
\hline $\mathrm{T}_{\mathrm{ti}}$ & the turbine time constant of control area i (s) \\
\hline$B_{i}$ & frequency bias constant of area i \\
\hline$T_{p i}$ & $2 \mathrm{H}_{\mathrm{i}} / f^{*} \mathrm{D}_{\mathrm{i}}$ \\
\hline $\mathrm{K}_{\mathrm{pi}}$ & $1 / D_{i}(\mathrm{~Hz} / \mathrm{pu})$ \\
\hline $\mathrm{K}_{\mathrm{pi}}$ & proportional gain of PI, PID, PIDF, and PIDF plus $(1+\mathrm{PI})$ controller in the control area \\
\hline $\mathrm{K}_{\mathrm{li}}$ & integral gain of integral, PI, PID, PIDF and PIDF plus $(1+\mathrm{PI})$ controller in control area $\mathrm{i}$ \\
\hline$K_{\mathrm{Di}}$ & derivative gain of PID, PIDF, and PIDF plus $(1+\mathrm{PI})$ controller in the control area i \\
\hline$K_{\mathrm{ppi}}$ & the proportional gain of $(1+\mathrm{PI})$ controller in the control area i \\
\hline $\mathrm{N}_{\mathrm{i}}$ & filter coefficient of PIDF \& PDF controller in control area i \\
\hline $\mathrm{D}(\mathrm{s})$ & estimated derivative term $=s / 1+\mathrm{Ns}$ \\
\hline$\beta i$ & control area frequency response characteristics of area I (AFRC) $=D_{i}+1 / R_{i}$ \\
\hline$\Delta f i$ & frequency incremental of control area i $(\mathrm{Hz})$ \\
\hline$\Delta \mathrm{P}_{\mathrm{gi}}$ & Generation increments of control area i (p.u) \\
\hline$\Delta P_{\text {tie }}$ i-j & tie-line power increment among control area i and area j (p.u) \\
\hline $\mathrm{T}$ & simulation time $(s)$ \\
\hline
\end{tabular}




\section{Acknowledgements}

Not applicable.

\section{Authors' contributions}

The first author developed the models and obtained the results. The second author implemented the optimization algorithm and tested on OPAL-RT. The third author suggested the controller and validated the manuscript. The author(s) read and approved the final manuscript.

\section{Author's information}

Pratap Chabdra Nayak is a Ph.D research Scholar in the Department of Electrical Engineering, VSSUT, Burla, 768018, Odisha, India. Ramesh Chandra Prusty is working as Assistant Professor in the Department of Electrical Engineering, VSSUT, Burla, 768018, Odisha, India. Sidhartha Panda is working as Professor in the Department of Electrical Engineering, VSSUT, Burla, 768018, Odisha, India.

\section{Funding}

Not applicable.

\section{Availability of data and materials}

Not applicable.

\section{Competing interests}

The author declares that they have no competing interests.

\section{Received: 19 March 2020 Accepted: 8 February 2021}

\section{Published online: 19 March 2021}

\section{References}

1. Elgerd, O. L. (2000). Electric energy systems theory - An introduction, Tata Mc Graw Hill, New Delhi.. Clerk Maxwell, a treatise on electricity and magnetism, (vol. 2, 3rd ed. pp. 68-73). Oxford: Clarendon, 1892. https:/doi.org/10.1007/978-1-4615-5997-9_6.

2. Fosha, C. and Elgerd, O.I. (1970), "The megawatt-frequency control problem: A new approach via optimal control theory", IEEE transactions on power apparatus and systems, PAS-89 4, 563-577, DOl: https://doi.org/10.1109/TPAS.1970.292603.

3. Kundur, P. (2006). Power System Stability and Control. New Delhi: Tata McGraw, https://www.mheducation.co.in/power-system-stability-andcontrol-9780070635159-india.

4. Hingorani, N. G., \& Gyugyi L. (2000). Understanding FACTS: Concepts and Technology of Flexible AC Transmission Systems. Wiley-IEEE Press, https:// ieeexplore.ieee.org/servlet/opac?bknumber=5264253.

5. Praghnesh, B., Ranjit, R., \& Ghoshal, S. P. (2011). Comparative performance evaluation of SMES-SMES, TCPS-SMES, and SSSC-SMES controllers in automatic generation control for a two-area hydro-hydro system. International Journal of Electrical Power \& Energy Systems, 33(10), 1585-1597. https://doi.org/10.1016/j.ijepes.2010.12.015.

6. Sahu, P. R., Hota, P. K., \& Panda, S. (2018). Power system stability enhancement by fractional-order multi-input SSSC based controller employing whale optimizing algorithm. Electrical Systems and Information Technology, 5(3), 326-336. https://doi.org/10.1016/j.jesit.2018.02.008.

7. Praghnesh, B., Ranjit, R., \& Ghoshal, S. P. (2012). Coordinated control of TCPS and SMES for frequency regulation of interconnected restructured power systems with dynamic participation from DFIG based wind farms. Renew Energy, 40, 40-50. https://doi.org/10.1016/.j.renene.2011.08.035.

8. Chidambaram, I. A., \& Paramasivam, B. (2012). Control performance standards-based load frequency controller considering redox flow batteries coordinate with an interline power flow controller. Journal of Power Sources, 219, 292-304. https://doi.org/10.1016/j.jpowsour.2012.06.048.

9. Chidambaram, I. A., \& Paramasivam, B. (2013). Optimized load-frequency simulation in restructured power system with redox flow batteries and interline power flow controller. International Journal of Electrical Power \& Energy Systems, 50, 9-24. https://doi.org/10.1016/j.jijepes.2013.02.004.

10. Guo C., Tong L., \& Wang Z. (2002). Stability control of TCSC between interconnected power networks. Proceedings. International Conference on Power System Technology, Kunming, China, 3, 1943-1946, https://doi.org/1 0.1109/ICPST.2002.1067872

11. Wadhai, S. D., \& Ghawghawe, N. D. (2011). Power flow control by using TCSC controller in the power system. In $i$-COST electronics and communication conference proceeding, (pp. 27-33). https:/doi.org/10.4010/2016.569.
12. Pradhan, P. C., Sahu, R. K., \& Panda, S. (2015). Firefly algorithm optimized fuzzy PID controller for AGC of multi-area multi-source power systems with UPFC and SMES. Engineering Science and Technology an International Journal, 2015, 338-354. https://doi.org/10.1016/j.jestch.2015.08.007.

13. Sahu, R. K., Panda, S., \& Yegireddy, N. K. (2014). A novel hybrid DEPS optimized fuzzy PI/PID controller for load frequency control of multi-area interconnected power systems. Journal of Process Control, 24(10), 1596-1608. https://doi.org/10.1016/j.jprocont.2014.08.006.

14. Saikia, L. C., Nanda, J., \& Mishra, S. (2011). Performance comparison of several classical controllers in AGC for multi-area interconnected thermal system. Electrical Power and Energy Systems, 33, 394-401. https://doi.org/10.1 016/j.ijepes.2010.08.036.

15. Sahu, R. K. Panda, S. \& Rout, U. K. (2013). DE optimized parallel 2-DOF PID controller for load frequency control of power system with governor deadband nonlinearity. Electrical Power and Energy Systems, 49, 19-33. https://doi. org/10.1016/j.jijepes.2012.12.009

16. Nayak, P. C., Prusty, U. C., Prusty, R. C., \& Barisal, A. K. (2018). Application of SOS in fuzzy based PID controller for AGC of multi-area power system. IEEE Conference on Technologies for Smart - City Energy Security and Power, 1, 16. https://doi.org/10.1109/ICSESP.2018.8376709.

17. Demiroren, A., \& Yesil, E. (2004). Automatic generation control with fuzzy logic controllers in the power system including SMES units. Electrical Power and Energy Systems, 26, 291-305. https://doi.org/10.1016/j.asej.2014.03.011.

18. Nayak, P. C., Sahoo, A., Balabantaray, R., \& Prusty, R. C. (2018). Comparative study of SOS \& PSO for fuzzy based PID controller in AGC in an integrated power system. IEEE Conference on Technologies for Smart - City Energy Security and Power, 1, 1-6. https://doi.org/10.1109//CSESP.2018.8376700.

19. Dash, P., Saikia, L. C., \& Sinha, N. (2015). Automatic generation control of multi area thermal system using bat algorithm optimized PD-PID Cascade controller. Electrical Power and Energy Systems, 68, 364-372. https://doi.org/1 0.1016/j.ijepes.2014.12.063.

20. Padhy, S., \& Panda, S. M. (2017). A modified GWO technique-based cascade PI-PD controller for AGC of power systems in presence of plug-in electric vehicles. Engineering Science and Technology, 20(2), 427-442. https://doi. org/10.1016/j.jestch.2017.03.004.

21. Sahu, P. C., Prusty, R. C., \& Panda, S. (2019). A gray wolf optimized FPD plus (1+ PI) multistage controller for AGC of multisource non-linear power system. World Journal of Engineering. https://doi.org/10.1108/WJE-05-2018-0154.

22. Nayak, P. C., Prusty, R. C., \& Panda, S. (2020). Grasshopper optimization algorithm of multistage PDF+(1+ PI) controller for AGC with GDB \& GRC nonlinearity of dispersed type power system. International Journal of Ambient Energy, 1-21. https://doi.org/10.1080/01430750.2019.1709897.

23. Dash, P., Saikia, L. C., \& Sinha, N. (2015). Comparison of performances of several FACTS devices using cuckoo search algorithm optimized 2DOF controllers in multi-area AGC. Electrical Power and Energy Systems, 65, 316324. https://doi.org/10.1016/.jijepes.2014.10.015.

24. Tasnin, W. \& Saikia, L. C. (2019). Impact of renewables and FACT device on deregulated thermal system having sine cosine algorithm optimised fractional order cascade controller. IET Renewable Power Generation, 13(9), 1420-1430. https://doi.org/10.1049/iet-rpg.2018.5638.

25. Saremi, S., Mirjalili, S., \& Lewis, A. (2017). Grasshopper optimization algorithm: Theory and application. Advances in Engineering Software, 105, 30-47. https://doi.org/10.1016/j.advengsoft.2017.01.004

26. Khooban, M. H. (2017). Secondary load frequency control of time-delay stand-alone micro-grids with electric vehicles. IEEE Transactions on Industrial Electronics, 65(9), 7416-7422. https://doi.org/10.1109/TIE.2017.2784385. 